\title{
Defensa y justificación de la dinastía Trastámara. Las Crónicas de Pedro López de Ayala
}

\author{
JOSE-LUIS MARTIN *
}

Las limitaciones de tiempo que todo curso tiene hicieron imposible tratar en Ávila todos y cada uno de los aspectos comprendidos en el ambicioso título "La Corona de Castilla **, Siglo XV" y entre los aspectos "olvidados" merecen al menos una mención los años finales del siglo XIV que nadie conoció mejor que el caballero, poeta, diplomático, canciller y cronista Pedro López de Ayala, autor de las Crónicas de Pedro I, Enrique II, Juan I y, parcialmente, Enrique III cuyo reinado se inicia precisamente en 1390, hace ahora seiscientos años aunque el centenario haya pasado desapercibido, como tantos otros, absorbido por la proximidad del único centenario que parece interesar en los momentos actuales, olvidando que 1492 fue posible porque en el siglo XIV se consolidó la dinastía Trastámara en Castilla y extendió su acción por los demás reinos peninsulares, que los viajes de Colón no habrian tenido lugar si desde el siglo XIV los marinos y mercaderes castellanos no hubiesen intervenido activamente en el Atlántico, en competencia con los portugueses, ingleses y hanseáticos...

Releer una vez más a Pedro López de Ayala puede ayudarnos a entender los años finales del siglo xv, a comprender 1492 que no es sólo el año del "Descubrimiento" sino también el año de la expulsión de

* Universidad Nacional de Educación a Distancia.

** N. de la R.-El autor se refiere al ciclo de conferencias celebrado en Ávila en julio de 1990, que se publicarán en el próximo número de la serie III de E.T.F. 
judios y musulmanes, consecuencia o efecto de una política iniciada mucho antes.

\section{HISTORIA Y POLITICA}

Cronista de excepción, Pedro López de Ayala no es, sin embargo, un historiador objetivo aunque en el proemio a su obra señale que cuenta lo que vio personalmente, "en lo qual non entiendo decir sinon verdad", $y$ lo que le narraron "Señores e Caballeros e otros dignos de fe e de creer, de quienes lo oí e me dieron dende testimonio" '. López de Ayala es un noble y como tal expresa el punto de vista de la nobleza que triunfa, al lado de Enrique de Trastámara, sobre el monarca legítimo del que se destacan las crueldades para justificar o al menos explicar la oposición nobiliaria. De la tiranía de Pedro I comienza a hablarse en el primer año de su reinado: Enrique, sus hermanos y su madre no acompañan el cuerpo de su padre y amante Alfonso XI a Sevilla por urescelo e miedo que avia del Rey Don Pedro", miedo que, por otra parte, está justificado pues un año más tarde Leonor de Guzmán, madre de Enrique, fue ejecutada por orden del rey; su muerte da ocasión al cronista para recordar que esta muerte «pesó mucho a algunos del regno; ca entendian que por tal fecho como éste vernían grandes guerras e escándalos en el Regno, segund fueron después". Al descontento de los nobles se une el del pueblo, que sufre los efectos de la mala administración, de la avaricia y de la crueldad de un monarca al que no faltan virtudes $y$ cualidades junto a sus numerosos defectos: «Era muy cazador de aves. Fue muy sufridor de trabajos. Era muy temprado e bien acostumbrado en el comer e beber. Dormía poco e amó mucho mugeres ${ }^{2}$. Fue muy trabajador en guerra. Fue cobdicioso de allegar tesoros e joyas... E mató muchos en su Regno, por lo qual le vino todo el daño que avedes oído" son las penúltimas palabras del cronista sobre el rey al que sivió durante años y al que ahora aplica las palabras del Profeta David: "Agora los

' Cronicas de los Reyes de Castilla I, Madrid 1953.

2 En la pluma de López de Ayala, amar "mucho mugeres" puede ser una alabanza, si recordamos que Fernán Pérez de GuzMAN, Generaciones y Semblanzas, Londres 1965, pág. 15, termina el "retrato" de Ayala diciendo: "Amó mucho mugeres, más que a tan sabio cavallero como él se convenia". 
Reyes aprended, e sed castigados todos los que juzgades el mundo ca grand juicio e maravilloso fue éste, e muy espantable».

Las Crónicas, redactadas en "hermoso y alto estilo" como quería Fernán Pérez de Guzmán, nos han llegado en dos versiones conocidas tradicionalmente con los nombres de "vulgar» y de "abreviada", nombres que pueden inducir a confusión pues mientras la llamada "vulgar" llega hasta la muerte de Juan I, hasta 1390, la "abreviada" incluye los primeros años del reinado de Enrique III; el calificativo de abreviada procede no de la extensión cronológica sino de tener menos capítulos o haber resumido éstos por razones en las que no siempre están de acuerdo los historiadores.

La existencia de las dos versiones fue explicada por Jerónimo Zurita para quien primero se escribiría la versión "abreviada", y la "vulgar» sería una ampliación en la que, de paso, se suprimieron «algunas cosas que estando ya fundada la sucesión del Reyno, parecia que podian ofender»; la "vulgar", más amplia y mejor documentada, sería también más "política" por cuanto se habrian suprimido frases o expresiones escritas al calor de acontecimientos políticos que años después carecian de relevancia o interesaba olvidar al haberse producido la reconciliación entre los bandos enfrentados ${ }^{3}$.

Michel García acepta, con matices ${ }^{4}$, este asunto, pero sólo hasta el reinado de Enrique II: “en los últimos años del reinado de Enrique II y, sin discusión posible, a partir del año 1378 , la relación establecida tradicionalmente entre las dos versiones de las crónicas queda invertida;... la versión que seguiremos llamando vulgar... aparece como una primera versión, y la abreviada, como una versión revisada».

Anterior o posterior, la "vulgar" añade capítulos enteros en cada uno de los años desde 1351 y 1373 , ofrece detalles no incluidos en la "abreviada" y reescribe, incluso formalmente, algunas noticias, datos que confirman, según Michel Garcia, "que el cronista volvió a redactar su texto, principalmente para aportar una información complementaria...", y en

${ }^{3}$ El historiador aragonés del siglo xVI fue el primero en preparar una edición de las Crónicas, aunque éstas no se publicaron hasta 1779-1780 con algunas correcciones y notas añadidas por Eugenio de Llaguno Amirola; esta versión es la publicada por la Biblioteca de Autores Españoles, que utilizamos en este trabajo.

${ }^{4}$ Michel Garcia ha comparado diversos manuscritos para determinar las diferencias entre ambas versiones, y tras probar que la "vulgar" es generalmente más amplia, encuentra algunos casos en los que faltan en la "vulgar" aspectos que figuran en la versión "abreviada" (Obra y personalidad del Canciller Ayala, Madrid 1982, págs. 97-155, y de manera especial la pág. 142 y ss.). 
otros casos para "sugerir una interpretación de los acoritecimientos históricos, bajo la presión de personas o grupos interesados en que la historia se escribiese para dar una imagen favorable de su actuación...» ${ }^{5}$.

A partir del reinado de Enrique II, las diferencias de contenido entre las versiones disminuyen, la "abreviada" contiene al menos un capítulo que no figura en la "vulgar" y el texto de la "abreviada» aparece reescrito en numerosas ocasiones por razones estilísticas o para incluir detalles no mencionados en la "vulgar»; la confusión aumenta si se considera que ninguno de los códices conservados contiene integramente y de manera exclusiva una de las versiones: "todos mezclan las dos versiones: los de la vulgar reproducen una primera parte revisada y una segunda parte primitiva; los de la abreviada empiezan con la versión primitiva, para terminar con la revisada..." ${ }^{6}$, por lo que las dudas se mantendrán hasta que dispongamos de una edición critica que tenga en cuenta los códices de las dos versiones con todas y cada una de las variantes en ellos contenidas.

Por el momento y siguiendo el estudio de Michel García podemos aceptar que el proyecto de escribir estas crónicas nace en el reinado de Juan I, probablemente después de Aljubarrota -1385-, en un intento de fijar "la verdad oficial sobre un período muy agitado y controvertido de Castilla". La versión inicial seria revisada en los años finales del siglo XIV o a comienzos del XV por el propio canciller, y posteriormente las crónicas sufririan nuevos retoques a manos de copistas que añadieron datos de "actualidad" que evidentemente Ayala no pudo conocer: en 1380 se habla de la sucesión de Carlos V de Francia y se añaden noticias relativas a "veynte e tres días del mes de nobiembre del año del Nuestro Señor Ihesu Christo de mill e quatroçientos e siete años", posterior a la muerte del cronista, como es posterior el nombramiento de Fernando de Antequera como rey de Aragón, que tuvo lugar en $1412 \ldots$ Posiblemente fue continuador, corrector o reescritor de las Crónicas Fernán Pérez de Ayala, hijo del Canciller, al que, no obstante, corresponde el mérito fundamental del trabajo.

Algunos manuscritos de la versión "abreviada" se inician con un prólogo o presentación redactado por Ayala en tiempos de Enrique III en el que resume su concepto y sentido de la Historia.

${ }^{5}$ Obra citada, pág. 127. En ocasiones, López de Ayala intenta despersonalizar el relato y oculta o encubre su participación.

6 Ídem, pág. 154. 
Se inicia el proemio con una apología de la escritura, inventada porque la "memoria de los omes es muy flaca» y no puede recordar "las sciencias e grandes fechos que acaescieron en el mundo", que han de servir de ejemplo "para facer bien e se guardar de mal" todos los hombres y de modo especial los príncipes y reyes; por esta razón, los príncipes antiguos ordenaron que se hicieran libros llamados crónicas en los que se escribieran las caballerias y demás hazañas para que reyes y príncipes posteriores "leyéndolas, tomasen mejor e mayor esfuerzo de facer bien e de se guardar de facer mal'. La historia se escribe, pues, por orden y al servicio de reyes y principes, en este caso por orden y para servir los intereses de los reyes de la dinastía Trastámara, cuya ilegitimidad la hace vulnerable a los ataques de los enemigos del interior y externos ${ }^{\text {. }}$.

\section{DE LA REVUELTA NOBILIARIA A LA GUERRA DE LOS CIEN AÑOS}

La revuelta de los nobles castellanos dirigida por Enrique de Trastámara habría carecido de importancia $^{8}$ si no hubiera coincidido en el tiempo con la guerra castellano-aragonesa (la llamada "Guerra de los dos Pedros") y con los enfrentamientos entre franceses e ingleses (Guerra de los Cien Años), conflictos con los que se relacionan otros enfrentamientos menores que, juntos, desembocan en lo que podemos llamar la primera guerra europea en la que intervienen todos los reinos peninsulares, las repúblicas italianas, el pontificado, el Imperio alemán, Escocia, Flandes, las ciudades alemanas a través de la Liga Hanseática, las ciudades del Cantábrico organizadas en la hermandad de la Marisma o de la Marina de Castilla, los artesanos y mercaderes de Portugal...

Los rebeldes castellanos buscan ayuda en el exterior y como en tantas otras ocasiones encuentran el apoyo del monarca aragonés, en

${ }^{7}$ En las páginas que siguen intentaré resumir el contenido, los aspectos fundamentales o más interesantes, de cada una de las Crónicas, comenzando lógicamente por la de Pedro I cuyos últimos años coinciden con los de Enrique II, proclamado rey en 1366 con la ayuda de las compañias francesas dirigidas por Beltran Du Guesclin.

${ }^{8}$ Revueltas nobiliarias de mayor gravedad tuvo que reprimir Alfonso XI, y Pedro I se vio envuelto en conflictos más serios en los primeros años de su reinado. 
guerra con Castilla desde 1356 por cuestiones fronterizas y por la colaboración de Castilla con Génova, enemiga tradicional de Cataluña por el control del Mediterráneo ${ }^{9}$. La guerra es favorable al monarca castellano, que dispone de medios económicos muy superiores a los de su enemigo ${ }^{10}$, y los nobles castellanos se ven obligados a ganarse la vida ofreciendo sus servicios militares a los franceses hasta que Francia e Inglaterra firman una de las numerosas treguas que interrumpen la guerra llamada de los Cien Años; la presencia en suelo francés de compañías de mercenarios acostumbrados a vivir de la guerra y del pillaje es un peligro que el rey de Francia y el Pontífice, residente en Aviñón, intentarán alejar enviándolas a combatir en la Península al servicio de Enrique de Trastámara que se ha proclamado rey de Castilla; con esta medida no sólo se aleja el peligro de suelo francés sino que se consigue el apoyo castellano a Francia en el caso de que Enrique obtenga la victoria. Al lado de Enrique y de Francia estará de nuevo Pedro el Ceremonioso de Aragón, y el monarca de Castilla buscará apoyos en Inglaterra y en los demás reyes hispánicos al tiempo que acentúa sus contactos con Génova para crear problemas a Cataluña en el Mediterráneo ${ }^{11}$.

Entre los aliados y colaboradores de Pedro I figuran los musulmanes de Granada con los que, tras la muerte de Alfonso XI, se firman treguas que ni siquiera lograrán interrumpir las peticiones de los legados enviados por el Pontífice para poner paz entre Aragón y Castilla: en 1359 (cap. 2) el cardenal Guido de Boloña recuerda en la corte castellana que el papa tenía al rey "por escudo e defendimiento de la Christiandad por quanto sostenía la guerra con los Moros de allén mar e de aquen mar" y ahora, en cambio, el monarca prefiere combatir a un cristiano aunque "por esta guerra cesaba la guerra de los Moros enemigos de Fe de

${ }^{9}$ Las causas de la guerra con Aragón figuran en el capítulo 7 y ss. de 1356.

${ }^{10}$ El gran problema de Pedro el Ceremonioso es la falta de medios económicos personales y la dificultad de obtener subsidios de las Cortes con la suficiente rapidez para detener a los ejércitos castellanos. Frente a esta penuria, el monarca castellano dispone de medios económicos suficientes: mientras Pedro el Ceremonioso se ve obligado a recurrir a continuos préstamos y a empeñar sus joyas y las de su esposa, al morir Pedro I se valoraron las joyas de su cámara de treinta millones de maravedies en "piedras preciosas e aljófar e baxilla de oro e de plata e en paños de oro e otros apostamientos"; en moneda se encontraron setenta millones y las deudas de los arrendadores ascendian a otros treinta millones (cap. 3 y último de 1369) a pesar de que tres años antes fue capturada la nave en la que iba su tesoro formado por "treinta e seis quintales de oro e muchas joyas" (cap. 14 de 1366).

"Las alianzas y acuerdos con los reyes peninsulares o con franceses e ingleses son continuas por lo que no es posible individualizarlos; pueden verse algunos de estos pactos en los capitulos $2,16,23,24$ de $1366 ; 1$ de $1367 \ldots$ 
Jesucristo". De nada sirvieron los razonamientos del legado pontificio y la flota castellana, en la que tiene un importante papel Pedro López de Ayala, atacó Barcelona y dominó el Mediterráneo durante algún tiempo.

Sólo un año más tarde, y por razones que nada tenian que ver con los requerimientos pontificios, Pedro I intervino en Granada donde los partidarios de Pedro el Ceremonioso habian facilitado una revuelta contra el monarca aliado del castellano y éste, consciente de que los conflictos granadinos podían ser peligrosos "ca todos los ginetes avrian de ir al Andalucia para la guerra de los Moros e partirse de la guerra de Aragón...» firmó la paz con Pedro el Ceremonioso y atacó al Rey Bermejo, al usurpador del reino granadino en cuyo trono repuso a su aliado" ${ }^{12}$.

Por los mismos años en los que se producía la revuelta granadina, Pedro entraba en conflicto con uno de sus más fieles auxiliares, el tesorero judío Samuel Levi, nombrado para el cargo a comienzos del reinado. En 1355 (cap. 15), Pedro llamó indirectamente la atención del tesorero al quejarse públicamente de que todos sus bienes ascendian a la insignificante cantidad de veinte mil doblas en oro y plata ${ }^{13}$; en 1360 , Samuel fue detenido junto con todos sus parientes en un mismo día y sometido a tormento: se le encontraron ciento sesenta mil doblas, cuatro mil marcos de plata, ciento veinticinco arcas de paños de oro y de seda, otras joyas y ochenta moros, moras y moreznos; fueron confiscados a los parientes del tesorero trescientas mil doblas... Pese a esta actitud respecto al tesorero judio, los hebreos se mantuvieron fieles al monarca y vieron cómo sus aljamas en Burgos o en Toledo eran atacadas por los partidarios de Enrique II $^{14}$.

${ }_{12}$ Las relaciones con Granada pueden verse en los capitulos 23 de 1360, 5, 7 y 8 de 1361,1 y ss. de $1362 \ldots$ y 4 y 5 de 1368 . En estos capítulos se presenta al rey granadino con siete mil jinetes, ochenta mil peones y doce mil ballesteros colaborando con Pedro I en el ataque a Córdoba y Jaén, ciudades controladas por los partidarios de Enrique II.

${ }_{13}$ Pedro está jugando a los dados, utiliza las monedas de una arqueta y declara que alli está todo su tesoro. Samuel imagina que las palabras del monarca encubren un reproche a su gestión y se ofrece a reunir un gran tesoro si el monarca le da plenos poderes; recibidos éstos, manda llamar a los recaudadores y les obliga a pagar el dinero que habian cobrado en nombre del monarca y del que no habían hecho entrega; en otros casos, el recaudador no tenía que pagar al rey sino a un caballero o a un acreedor del monarca que. lógicamente, habia perdido toda esperanza de cobrar después de varios años; Samuel hace pagar las deudas, entrega la mitad al acreedor y el resto pasa a engrosar el tesoro real: "e el caballero... era muy contento e pagado, como aquel que los tenía perdidos...; e asi fue el comienzo del tesoro que el Rey Don Pedro fizo' (cap. 15).

El lesorero cristiano Martin Yáñez no tuvo mejor suerte que Samuel Levi: fue mandado ejecutar por Pedro I “diciendo que por él avía perdido su tesoro" (cap. 28 de 1367).

${ }_{14}$ La colaboración de los judíos con Pedro y los ataques de Enrique pueden verse en los capítulos 7 de 1365,7 y 8 de $1366 \ldots$ 


\section{ENRIQUE II: CONSOLIDACIÓN PENINSULAR DE LA DINASTIAA}

El control de los partidarios de Pedro es, lógicamente, la primera preocupación del nuevo monarca, pero tan importante o más que la pacificación interior era poner coto a las ambiciones de los monarcas peninsulares que aspiraban a compartir el reino de Castilla con Enrique y presionaban apoyando ahora a los petristas: Carlos II de Navarra reclamaba Logroño, Vitoria, Salvatierra y Santa Cruz de Campezo; Pedro el Ceremonioso de Aragón pretendia ampliar el reino de Valencia con tierras murcianas y ocupar algunas plazas fronterizas entre Aragón y Castilla; Fernando de Portugal se consideraba con más derechos al trono de Castilla que el conde de Trastámara, hijo ilegítimo de Alfonso XI, y los musulmanes de Granada se consideraban desligados de las treguas y paces firmadas con Pedro I; a estos problemas se añaden la necesidad de pagar los servicios de las compañias francesas y evitar una posible intervención inglesa.

Combatir a los enemigos y pagar a los amigos exige medios económicos de los que Enrique no dispone y que obtendrá o intentará obtener aumentando los impuestos y vendiendo o dando en pago de los servicios prestados diversos lugares de realengo, es decir, mediante lo que conocemos como "mercedes enriqueñas", a las que Pedro López de Ayala alude de pasada para recordar que esta práctica era peligrosa por cuanto enajenaba el apoyo de "muchas comarcas del Regno que tovieron su voz". Enrique acudirá también a la confiscación de los bienes de los rebeldes y a la acuñación de moneda de baja calidad, que resuelve momentáneamente los problemas del monarca: manda recoger la plata y el oro existentes y con este metal acuña nuevas monedas que valen oficialmente lo mismo y, sin embargo, tienen menor cantidad de oro o plata; el beneficio es tanto mayor cuanto peor sea la nueva moneda y a bajo precio pudo Enrique pagar la ayuda de Beltrán du Guesclin, de sus hombres y de "muchos de los suyos de mucho que les debía", pero el mercado no aceptó la nueva moneda y los precios subieron extraordinariamente (cap. 3 de 1369) y por esta razón "las viandas e armas e caballos e joyas e plata... se non podian comprar, ca valía un caballo bueno ochenta mil maravedies..., según declara el cronista en el año 1371 al contar cómo el monarca tuvo que reducir a la tercera parte el valor oficial de las monedas (cap. 8).

Tras dos años en los que Enrique se limita a defenderse y a resolver como buenamente puede los problemas económicos, en 1371 comienzan 
los éxitos del Trastámara: recupera Carmona y Zamora, controladas por los petristas, contiene a los granadinos, la flota castellana obtiene una importante victoria sobre la inglesa en aguas de La Rochela y, sobre todo, firma la paz con el monarca portugués, que le devuelve las plazas de La Coruña, Ciudad Rodrigo y Valencia de Alcántara. El éxito se ve oscurecido por la negativa de Fernando I a unirse en matrimonio con la infanta Leonor de Castilla, hija de Enrique. El rey castellano estaba especialmente interesado en el establecimiento de alianzas matrimoniales con los reyes de la Península para que éstos, al emparentar con la dinastía Trastámara, olvidaran la ilegitimidad de Enrique y dejaran de utilizarla como pretexto para apoyar a los castellanos rebeldes ${ }^{15}$.

La negativa de Fernando, justificada por su anterior y semisecreto matrimonio con la portuguesa Leonor Téllez de Meneses, enojó a Enrique, que disimuló por la "grand voluntad... de aver paz" y después de que Fernando ratificara su compromiso de devolver las plazas ocupadas a Castilla; tal vez se consoló pensando, con el cronista, "que a su fija la Infanta non le menguaría otro tan grand casamiento" (cap. 7), y asi fue: en 1373 se concertó el matrimonio de Leonor con el heredero de Navarra, y por lo que respecta a Portugal, este mismo año, se llegó a una triple alianza matrimonial: los castellanos Sancho, Fadrique y Alfonso serían prometidos a Beatriz, hermana del monarca portugués, y a sus hijas Beatriz e Isabel ${ }^{16}$.

También con Aragón se firmaron paces, ratificadas en este caso mediante el matrimonio del heredero castellano Juan con Leonor de Aragón, acordado años antes cuando Enrique era tan sólo un noble refu-

15 Ayala se detendrá en la narración del fallido matrimonio, y concede atención especial a la victoria naval de La Rochela, que deja el comercio atlántico en manos de los marinos de Castilla y, al mismo tiempo, alivia los problemas económicos de la monarquía al ocuparse el tesoro puesto a disposición del almirante inglés para la guerra y cobrarse rescate de los más de setenta caballeros "de espuelas doradas". Muchos de los auxiliares franceses de Enrique cobraron sus servicios mediante la entrega de estos prisioneros para que ellos mismos cobraran el rescate, y éste no fue to cuantioso que cabía esperar porque "muchos de los Caballeros que alli fueron presos morieron en la prisión" (cap. 10).

${ }^{16}$ Los matrimonios portugueses no tuvieron excesivo éxito: Sancho, conde de Alburquerque, murió en una pelea en Burgos en 1374: meses más tarde, su viuda dio a luz una hija a la que pusieron el nombre de Leonor y que con el tiempo se convertiría en la mujer más rica de Castilla y en esposa de su primo Fernando de Antequera (cap. 2 de 1374). Alfonso se negó a casarse y tuvo que ser obligado por Enrique (cap. 3 de 1375 y 1 de 1378), y Fadrique de Benavente se vio alejado del matrimonio con Beatriz cuando ésta se convirtió en heredera de Portugal: el apoyo del reino vecino podia ser peligroso para el rey de Castilla, y al morir Enrique II, Juan I se apresuró a cambiar al novio: sería su hijo, el futuro Enrique III, al que más tarde sustituirá el propio Juan I al enviudar de Leonor de Aragón (año 1382). 
giado en los dominios de Pedro el Ceremonioso. En 1374, Enrique escribe al rey de Aragón recordándole su promesa de enviar a Castilla a la infanta de acuerdo con lo convenido, y Pedro el Ceremonioso recuerda que el matrimonio es sólo una parte de lo acordado y que mientras Enrique no cumpla todos los puntos y entregue determinadas ciudades no habrá matrimonio. Finalmente, temiendo que podría haber guerra entre ellos, Pedro el Ceremonioso consintió en el matrimonio, y Enrique le hizo entrega de ochenta mil florines upor las despensas que facia en enviar su fija la Infanta en Castilla a facer sus bodas con el Infante Don Juan, e otrosí por algunas labores e costas que el Rey de Aragón ficiera en las villas de Molina e Requena". Soria fue durante el mes de mayo de 1375 la capital sentimental de Castilla: allí se casaron al mismo tiempo Juan de Castilla con Leonor de Aragón y Leonor de Castilla con Carlos de Navarra, cuyo padre recibió la cantidad de ciento veinte mil doblas, "las cien mil que el Rey Don Enrique daba con su fija la Infanta Doña Leonor en casamiento, e las veinte mil por costas e labores e despensas que el Rey de Navarra ficiera en las villas de Victoria e Logroño e Salvatierra" que ahora vuelven a poder del castellano ${ }^{17}$.

Junto a la política interior y peninsular preocupa al monarca y a su cronista la situación de la Iglesia, a cuya división dedica los capitulos 6 a 10 de 1378 en los que se narra la llegada de embajadores de Urbano VI y del Rey de Francia a la corte castellana y la respuesta dada por Enrique a unos y otros manifestando su intención de permanecer neutral hasta tener información más detallada, "que fasta todo esto ser visto e examinado, que su voluntad era de estar indiferente, e non tener por la una parte nin por la otra", y mientras la situación se aclaraba ordenó que el dinero que pertenecía al papa por cualquier concepto no fuera dado a ninguno de los papas elegidos, que lo «pusiesen en tesoro a buen recabdo, para los dar a aquel que fallasen todos los Christianos que era verdadero papa...” ${ }^{18}$.

17 La presión sobre Pedro el Ceremonioso para que se realice el matrimonio es al mismo tiempo militar y política en cuanto Enrique puede prestar su apoyo al rey de Mallorca, desironado por Pedro y refugiado en Castilla: “... por quanto el Rey Don Enrique era quejado del Rey de Aragón... plogóle de la guerra, e aun no estorvaba nin extrañaba a algunos suyos que ayudasen al Infante de Mallorcas, que agora era Rey de Napol, e entraban por algunas partidas en Aragón, diciendo que lo facían de su propia voluntad, sin mandado del Rey Don Enrique..." (cap. 7 de 1374).

${ }_{18}$ En el momento de la muerte. Enrique insiste ante su hijo en que "en razón de la Iglesia e de la cisma que hay en ella, que le ruego que haya buen consejo e sepa bien cómo debe fazer, ca es un caso muy dubdoso e muy peligroso..." (cap. 3 de 1379).

López de Ayala no deja de contarnos la desesperación de Enrique cuando se siente 


\section{JUAN I: FRACASOS Y EXITOS DE LA POLITICA MATRIMONIAL}

En páginas anteriores hemos señalado cómo uno de los objetivos de las crónicas era la justificación o legitimación de la dinastía Trastámara, y ésta nunca se vio más en peligro que durante el reinado de Juan I cuando el monarca castellano sufrió una importante derrota ante los portugueses que no lo aceptaban como marido de Beatriz de Portugal, y ante los ingleses dirigidos por Juan de Gante, duque de Lancaster y "rey» de Castilla por su matrimonio con Costanza, hija de Pedro I. Estos matrimonios y la guerra castellano-portuguesa ocupan casi en su totalidad el reinado y la crónica de Pedro López de Ayala, sin olvidar las alianzas internacionales con la monarquía francesa y con el pontífice de Aviñón, problemas internos derivados del enfrentamiento entre nobles y eclesiásticos por el control de los bienes de la Iglesia, o aspectos más o menos anecdóticos como la entrega del señorio de Madrid a León $V$ de Armenia ${ }^{19}$, o el intento de crear una nueva orden para premiar a los caballeros y escuderos del reino que más se distinguieran; el día de Santiago de 1390, en Segovia, Juan I crea lo que podemos llamar "Orden del Sol, de la Paloma o de la Rosa»: "dixo el Rey públicamente que él avia ordenado de traer una devisa... que era un collar fecho como rayos de sol, e estaba en el dicho collar una paloma blanca, que era representación de la gracia del Spiritu Sancto...; e diole a ciertos Caballeros suyos. Otrosí fizo otra devisa que traian escuderos suyos, que decian la Rosa, e los que querian probar los cuerpos justando o en otra manera, la traían...». La Orden no sobrevivió al monarca, que murió en octubre de este mismo año, pero el cronista recuerda que hizo todo esto "con

morir y ve que no llega el confesor: "Señor, pídote por merced que veas la mi voluntad, que yo te quería ver antes que saliese deste mundo".

${ }_{19}$ León $\mathrm{V}$ aparece citado por primera vez en el año 1380: prisionero del sultán de Babilonia (de los turcos) pide ayuda a los reyes cristianos para que lo liberen del cautiverio no tanto pagando el rescate cuanto suplicando al sultán: “non queria dineros por el Rey de Armenia, que asaz avía de oro e riquezas, mas quería que los Reyes Christianos ge to enviasen rogar e demandar que le soltasen por amor dello..." y como regalo enviasen objetos exóticos que no habia en su tierra: escarlatas, halcones, pieles... Liberado, León pasó por Castilla para agradecer el interés de Juan I y hacerle entrega de las cartas enviadas por el sultán. Juan dio al rey de Armenia, además de joyas y otros bienes, con carácter vitalicio "la villa de Madrid e la de Villareal e la de Andújar con todos sus pechos e derechos e rentas que en ellas avía..." (caps. 2-4 de 1383). 
muy buena entención; e si voluntad de Dios fuera que él viviera, su voluntad era de facer muy buenas ordenanzas» ${ }^{20}$.

\subsection{Resistencia portuguesa a la hegemonía castellana}

A petición de Fernando de Portugal, según Pérez de Ayala, en 1380 se modifican las alianzas matrimoniales, y Enrique, el heredero de Castilla, sustituye a su tío el duque de Benavente como marido de Beatriz de Portugal; a este acuerdo se añade una cláusula que podríamos llamar de filiación mutua entre los reyes de Castilla y de Portugal: si uno fallece sin hijos legítimos, el otro le sucederá en el reino. La posibilidad es remota pues tanto Fernando como Juan tienen hijos, pero la posibilidad de unir ambas Coronas aparece claramente manifestada y la confirman las Cortes reunidas en Soria.

Pese a estos acuerdos, se mantiene la alianza anglo-portuguesa y tropas inglesas mandadas por el conde de Cambridge desembarcan en Portugal - 1381- para con la ayuda de Fernando I defender los derechos al trono castellano del duque de Lancaster, casado con una hija de Pedro I. El cambio de actitud de Portugal pudo deberse a los recelos que suscitaba la posible unión a Castilla 0 , al menos, así se desprende de las palabras del cronista cuando en 1382 pone en boca de Fernando I la petición de que se anule el posible matrimonio de Beatriz con Enrique y se acuerde su unión con Fernando, hijo segundo de Juan I de Castilla: Fernando podría ser rey de Portugal "e non se mezclaría aquel Regno con el Regno de Castilla; lo qual non avria lugar si casase con el Infante Don Enrique, por ser heredero de Castilla».

La advertencia sobre el malestar portugués ante la unión con Castilla fue desoida por el monarca que, este mismo año al morir su esposa, Leonor de Aragón, envió embajadores a Portugal para anular el matrimonio de Fernando con Beatriz y proponerse a sí mismo como marido. La posibilidad de unir ambos reinos es lejana por cuanto Beatriz sólo será reina de Portugal si Fernando no tiene hijos varones, y en Castilla no reinará el posible hijo de Juan y Beatriz, pero la presencia de consejeros castellanos y la competencia entre marinos y mercaderes portugue-

20 1390, cap. 18. El interés por la caballería, probado además por la propuesta de combatir personalmente al maestre de Avis y evitar asi la guerra con Portugal, choca con el físico de Juan I: "non grande de cuerpo e blanco e rubio e manso e sosegado... e avia muchas dolencias..." (cap. 20 de 1390). 
ses y de Castilla harán que la unión sea mal vista en Portugal y que contra ella se subleven los burgueses de Porto y Lisboa, numerosos concejos y una parte importante de la nobleza tan pronto como muere Fernando I de Portugal y Juan de Castilla entra en Portugal a pesar de los consejos para que no centrase por fuerza nin con gente de armas en el dicho Regno".

La presencia del castellano en tierras portuguesas suscita los primeros recelos, injustificados en algunos $\operatorname{casos}^{21}$ y plenamente justificados en otros: cuando en Lisboa se acepta a Beatriz como reina, "a muchos... non les placía dello... especialmente por ser casada con el Rey de Castilla, rescelándose que el Regno de Portogal se mezclaría con el Regno de Castilla, e sería uno con él, do agora era Regno por sí...»; quienes así piensan, no tardarán en hailar un dirigente y candidato al trono en la persona de Juan, maestre de Avis, que accede al trono a pesar de su condición de hijo ilegítimo y de sometido a la regla cisterciense como caballero de Avis.

Todos los inconvenientes fueron obviados en las Cortes celebradas en Coimbra y la posición del maestre se reforzó militarmente mediante una nueva alianza con Inglaterra; juntos, ingleses y portugueses derrotaron a los castellanos en los campos de Aljubarrota en 1385; en ella cayó prisionero el cronista Pedro López de Ayala y a punto estuvo de ser preso el rey castellano que "como estaba flaco, leváronle en unas andas Caballeros e Escuderos que eran ordenados para la guarda de su cuerpo; e desque vieron la batalla vuelta, pusiéronle en una mula; e quando vieron que las gentes del Rey se retraian... estonces pusieron al Rey en un caballo, e sacáronle del campo, magüer estaba muy doliente». Pese a la importancia política de Aljubarrota, según confesión de López de Ayala, "duró la porfia de la batalla, antes que pareciese quáles perdían o ganaban, media hora asaz pequeña” (cap. 14 de 1385).

\subsection{Petristas y Trastámaras}

Tras la derrota militar, llegan a la corte castellana las pretensiones del aspirante al trono, que ocupa parte de Galicia y envía al rey Juan un heraldo para comunicarle "cómo él era venido en Galicia e traia consigo

21 Parecen poco serias las protestas de algunos nobles portugueses porque Juan I era hombre de pocas palabras y ellos estaban acostumbrados al trato con Fernando I "que era ome de grandes gasajados..." (cap. 11 de 1383). 
la Reyna Doña Costanza... e que venía demandar los Regnos de Castilla e de León por derecho que la dicha su muger Doña Costanza avía a ellos...", derechos que está dispuesto a defender "en batalla». Juan I responde con otra embajada en la que los papeles están perfectamente distribuidos: mientras unos niegan los derechos de Juan de Gante al trono de Castilla, otros se muestran partidarios de resolver las diferencias en combate personal "o diez a diez, o ciento a ciento, por... escusar derramamiento de sangre de christianos", y el prior de Guadalupe tiene órdenes de decir en secreto al duque de Lancaster «que el Duque non avía más de una fija... e que el Rey Don Juan avía un fijo, e que se ficiese casamiento dellos e serían herederos de los Regnos de Castilla e de León e cesaria esta quistión e guerra" (cap. 9 de 1386).

La defensa de los derechos al trono de los Trastámara tiene base histórica, lo que puede hacer pensar que en ella intervino el cronistahistoriador Pedro López de Ayala: los derechos no derivan de Enrique II - su ilegitimidad lo impide- sino de la mujer de éste, Juana, heredera legitima de Castilla como descendiente de Fernando de la Cerda, hijo de Alfonso $X$, que en su testamento desheredó a Sancho IV. Sancho no pudo heredar "por la non bendición del padre» y si él no heredó legítimamente tampoco lo hicieron Fernando IV. Alfonso XI, Pedro I o la hija de éste. A estas precisiones históricas responderá el duque de Lancaster recordando que él desciende de Leonor, hija de Fernando III, el conquistador de Sevilla, y atacando militarmente Castilla, aunque sin demasiado éxito debido a la peste que diezma a sus caballeros.

La peste, la falta de recursos para continuar la guerra y las desavenencias con el maestre de Avis ${ }^{22}$ llevaron al duque de Lancaster a negociar con Juan I sobre la base del matrimonio del heredero castellano con la hija del duque y el pago de una importante cantidad en compensación por los gastos efectuados: los duques recibirían seiscientos mil francos "del cuño de Francia" y mientras viviera uno de ellos la cantidad anual de cuarenta mil francos "de buen oro e justo peso"; si Enrique muriera antes de llegar al trono, Catalina de Lancaster casaría con Fernando o con quien estuviera llamado a heredar Castilla.

${ }^{22}$ En el primer momento, los ingleses acuden en ayuda del maestre de Avis y cobran sus servicios, pero cuando Juan de Gante pretende entrar en Castilla el rey de Portugal recuerda que deben pagarse los servicios de sus hombres y la dote de su mujer Felipa, hija del duque inglés (cap. 7 de 1387). 


\subsection{La obediencia al papa de Aviñón}

Los consejos dados por Enrique II en el lecho de muerte no fueron olvidados por Juan I, que hizo reunir en Medina del Campo a los letrados y prelados del Reino - 1380- para ver cuál de los dos papas era merecedor de la obediencia castellana; largamente se discutió en Medina, y finalmente, tras oír a unos y otros, Juan I decidió e hizo saber a los castellanos "que declaraba ser por el Papa Clemente VII e tener que aquel era Vicario de Jesu-Christo e sucesor de Sant Pedro", según comunica el 19 de mayo de 1381 en carta a "todos los fieles Christianos", que es en sí una breve historia del cisma (cap. 1 y 2 de 1381).

El pontífice no olvidará esta proclama, y al conocer la derrota del monarca castellano ante Portugal e Inglaterra (que siguen la obediencia del papa romano) le envía una carta condoliéndose porque "la tu gloria, e de toda España, que desde do el Sol nasce hasta el su ponimiento era temida de todos, por un arrebatamiento, apenas comenzado, cayó»; el pontífice recuerda que es voluntad de Dios que muchas veces el vencedor sea vencido "de otro más baxo" y cita diversos ejemplos tomados de la Biblia o de la historia más reciente para convencer al monarca de que no debe mostrar tanto dolor, pues conocido éste, "face a los tus amigos engendrar y acrescentar pesar, e acarrea grand placer a los enemigos..."; alude Clemente VII al luto ordenado en todo el reino por Juan I y mencionado de pasada en el capítulo 20 de la Crónica: "se vistió de paños prietos, e los traxo asi algunos días" ${ }^{23}$.

Las protestas contra la concesión de beneficios eclesiásticos a extranjeros han sido frecuentes en Castilla y quizá puedan ayudar a explicar la facilidad con la que se aceptó la "indiferencia» ordenada por Enrique II que fue acompañada del secuestro preventivo de los bienes pontificios; aceptado el papa de Aviñón cesa el secuestro y se reproducen las protestas de los castellanos que, con evidente exageración, afirman que no hay reino tan agraviado como el de Castilla: no se conoce ningún castellano o leonés que tenga "ningún beneficio grande nin menor en ningún otro Regno en Italia, nin Francia, nin en Inglaterra, nin en Portogal, nin en Aragón; e que de todos estos Regnos e tierras eran muchos que avian beneficios e dignidades en los Regnos de Castilla" con los lógicos perjuicios para el Reino: los beneficiarios no viven en el

${ }^{23}$ El luto aparece más claramente detallado en las Actas de las Cortes celebradas en Valladolid en 1385; también en eltas se le pide que abandone el luto pues de él se alegran los enemigos. 
reino y llevan fuera sus beneficios «e así se sacaba la buena moneda de la tierra", las iglesias estaban mal servidas y disminuian las vocaciones eclesiásticas pues los naturales del Reino «non querían facer fijos nin parientes clérigos pues non podian aver beneficios en Castilla" ${ }^{24}$.

\subsection{La Historia al servicio del presente}

Voluntariamente u obligado por las circunstancias, Juan I consulta en repetidas ocasiones a los miembros de su Consejo y en casi todas las ocasiones -el portavoz de los caballeros es Pedro López de Ayalaaprovecha la ocasión para recordar la Historia y extraer de ella las lecciones oportunas. Así, por ejemplo, cuando en 1385 ve que la guerra es inevitable y que ésta puede complicarse por la actuación de su hermanastro el conde Alfonso de Noreña pregunta qué debe hacer con quien ha sido acusado de traición; los clérigos se excusan: «ellos non podian fablar, por quanto era fecho de muerte"; uno de los caballeros se limita a decir que se aplique el derecho y el fuero de Castilla y de León, es decir, que se le condene a muerte porque si ha cometido tantos yerros en vida del rey, "de presumir es que faría mucho más si algo aconteciese de vos, fincando vuestro fijo el infante primogénito e heredero en la edad que está".

Otro caballero, presumiblemente Pedro López de Ayala, pide reflexión para que el rey no caiga en el error de sus antecesores, conocidos en el mundo entero por haber matado "arrebatadamente e sin forma de justicia a algunos Grandes de sus Regnos", y cita los casos de Alfonso $\mathrm{X}$ haciendo matar a su hermano Fadrique y a Simón de los Cameros, lo que provocó una revuelta nobiliaria; de Sancho IV, que hizo asesinar en Alfaro a don Lope, señor de Vizcaya; de Alfonso XI, que "mató sin ser oído" a don Juan Alfonso, señor de los Cameros, o al maestre de Alcántara..., por lo que el monarca deberá buscar jueces apropiados que no decidan por agradar al rey, es decir, jueces de fuera del reino para que no se pueda decir que los alcaldes del rey hacen lo que éste manda..., y propone como ejemplo digno de imitación el dado por el rey de Francia, que descontento de Carlos de Navarra le dio la oportunidad

${ }^{24}$ Se quejan igualmente del agravio comparativo que supone, en una iglesia donde hay un canónigo castellano y otro extranjero, pagar al segundo treinta mil maravedies, y sólo mil al primero (cap. 7 de 1390). 
de defenderse contratando a los mejores abogados que pudiera hallar, que serían pagados por el francés.

La experiencia y el conocimiento de los hechos históricos hablan por boca del anciano caballero francés que asiste al consejo en el que se discute sobre si conviene atacar o esperar que portugueses e ingleses abandonen las posiciones ventajosas que ocupan y tomen la iniciativa; el caballero, de setenta años, toma partido por la espera basándose en que los reyes de Francia en dos batallas han sido vencidos por Inglaterra precisamente por haber tomado la iniciativa. Su consejo agradó al rey pero no a los jóvenes cabalieros que acusando de cobardes a los demás se lanzaron al combate y fueron destrozados.

Las derrotas no desaniman al monarca castellano que, en 1390 , reúne a su consejo para exponerle una nueva idea que, según él, permitirá atraerse a los portugueses. Juan propone renunciar al trono en favor de su hijo Enrique y reservarse para sí, con carácter vitalicio, las ciudades de Sevilla y Córdoba, el obispado de Jaén, el reino de Murcia y el Señorío de Vizcaya; los de Portugal "veyendo esto se llegarían a él, e le obedescerian por su Rey e non avrian ya temor del ayuntamiento de los Regnos, pues traeria las armas de Portogal sin mezclamiento de las de Castilla, e el título de Rey de Portogal'". Los nobles desaniman al rey haciéndole ver que jamás lo aceptarán los portugueses y recordándole que bien sabe "por crónicas e libros de los fechos de España que son en la vuestra Cámara, e los leen delante vos quando a la vuestra merced place..." el daño que han producido las divisiones de los reinos desde la época de Fernando I, pasando por Alfonso VI, con el que Portugal se desvinculó de León, o por Alfonso VII, que dividió de nuevo Castilla y León (cap. 2).

\subsection{El Rey ante las Cortes}

Derrotado, amenazado por ingleses y portugueses y sin dinero, Juan I recurre a las Cortes que son convocadas estos años en Valladolid, Segovia, Briviesca, Guadalajara... Ayala menciona estas reuniones pero sólo concede espacio e importancia a las celebradas en Guadalajara, en las que Juan I expuso su deseo de renunciar al trono. Juan ha convocado a los procuradores diciéndoles que al firmar treguas con Portugal puede aliviar la presión fiscal a que el reino ha estado sometido, pero en secreto ha hablado con algunos de los representantes de los concejos para que convenzan a los demás y hagan un donativo para "poner en 
tesoro" pues los ingresos normales están gastados antes de cobrarse en el pago de los vasallos y oficiales, los gastos de la casa, embajadas, compensaciones a quienes perdieron todo en la guerra portuguesa. El señuelo para convencer a los procuradores es la posibilidad de crear un tesoro que, en su día, servirá para atacar de nuevo a Portugal y vengar la derrota sufrida: "para entonces --al finalizar las treguas- los fijos de los Señores e Caballeros que eran finados serian los más en edad para ir con él en su servicio a la dicha batalla».

La llamada al patriotismo llegó tarde: los procuradores habian tenido noticias del proyecto real y aun cuando se les ofreció la posibilidad de nombrar un tesorero responsable de cuanto se recaudase y obligado a no dar nada salvo para la guerra de Portugal, respondieron que el Rey ingresaba anualmente 35 millones y que nadie sabía en qué se gastaban por lo que, antes de votar una nueva ayuda, había de comprobarse si los ingresos ordinarios bastaban, suprimiendo los gastos superfluos o indebidos entre los que figuran los de tipo militar: muchos cobran sueldos del rey por tener caballo y armas y o no los tienen o no se presentan cuando se les requiere. Consecuencia de este cambio de impresiones fue el ordenamiento de lanzas hecho en Cortes, no sin problemas, pues, como afirma Juan I, en diversas ocasiones se ha intentado poner orden en los efectivos militares que reciben cuantías del Rey pero nunca ha sido posible y los ordenamientos no han sido respetados pues aunque todos son conscientes de que el dinero y las tierras que se dan a las gentes de armas son excesivos y se gastan mal, cuando se intenta cualquier arreglo todos, comenzando por los miembros del Consejo, «piden merced por los suyos", nadie acepta que se rebajen sus ingresos y no faltan quienes afirman que el monarca quita las tierras a los que las merecen "e que las dejo a los que las non merescian aver..." (caps. 5 y 6 de 1390).

\section{ENRIQUE III: EL PODER DE LA GRAN NOBLEZA}

El primer Trastámara encumbra a sus familiares hasta ponerlos al frente de las grandes familias a las que neutraliza, además, impulsando la creación de una nobleza de segundo orden fiel a la monarquía; el sistema de control de la nobleza funciona durante la primera generación; después, la segunda nobleza adquiere el poder y las ambiciones de la antigua y dispone siempre de un familiar del rey descontento y dispuesto 
a encabezar la revuelta o, más productivo, a controlar al monarca, especialmente si éste es débil como Juan $\mathrm{I}^{25}$ o menor de edad como Enrique III.

\subsection{El testamento de Juan I y la lucha por el poder}

El temor a las consecuencias de una minoria hace que cuando Juan I muere a consecuencia de una caída de caballo ${ }^{26}$ el arzobispo de Toledo, Pedro Tenorio, intente ocultar su muerte durante algún tiempo hasta haber controlado la situación: «fizo traer luego una tienda e armóla allí do el Rey yacía, e fizo venir los físicos e facer fama que el Rey non era muerto... E esto facía por aver espacio de enviar cartas por el Regno... por las quales facía saber... que catasen de guardar lealtad, a que eran tenudos, al Príncipe Don Enrique..." (Crónica de Juan I).

Pese a estas precauciones, inmediatamente después de jurar al nuevo rey, de once años y cinco días, comienzan las desavenencias sobre quién controlará al monarca. Pedro Tenorio es partidario de que se cumpla la voluntad de Juan I y solicita la colaboración de Pedro López de Ayala para localizar el testamento real y hacerlo valer en caso necesario. Sus enemigos niegan validez política al testamento basándose en que fue hecho años antes y el rey había cambiado de intención; el arzobispo lo reclama diciendo que si no tiene validez política sí servirá al menos para conocer las mandas piadosas "pues eran obra de piedad e limosna por el alma del Rey», y reclamará la aplicación de la voluntad real cuando los hechos demuestren que no es viable un Consejo de regencia controlado por los familiares del monarca que se presentan en la iglesia donde se reúne el Consejo «las cotas vestidas e las espadas ceñidas en tal guisa que los que ovieron de estar en Consejo non asosegaron bien las voluntades..." (cap. 6 de 1391). Y el reino se dividió en dos bandos por razón del testamento según declara Ayala en el capítu-

${ }^{25}$ Pese a los ruegos de Carlos III de Navarra y a su propio interés, Juan I fue incapaz de conseguir que abandonara la corte castellana su hermana Leonor, casada con Carlos de Navarra, al que la infanta castellana acusa de haber propiciado su envenenamiento o, al menos, de no haber hecho lo posible para saber por orden de quién le dio hierbas venenosas "un judio su físico que curaba de mi en aquella dolencia..." (cap. 8 de 1390, Crónica de Juan I).

${ }_{26}$ Murió pasando revista a unos caballeros cristianos cuyos padres se habían instalado en África en el momento de la ocupación de la Península por los musulmanes, al servicio del conde don Julián, y regresan ahora con "sus mugeres e fijos". 
lo 23 de 1391: "Así como los Señores... eran departidos... así se ficieron las cibdades e villas del Regno dos partes, que las unas tenían la parte del testamento, e las otras tenian la parte del Consejo..." hasta que las Cortes, reunidas en Burgos, acordaron en 1392 que se guardase el testamento del rey Juan «sin ser añadido ninguno más por Regidor e Tutor, nin Duque, nin Conde Don Alfonso, nin Conde Don Pedro, nin Maestre de Santiago... porque todos decían que non querían que ninguno de los grandes Señores que el Rey Don Juan non dejara por Tutores en el testamento oviese parte en el gobernamiento por ninguna manera...".

A este acuerdo se llega por unanimidad de los representantes de las ciudades y concejos, que no dudan en cambiar su voto para poner fin a la división: los procuradores depositaban su voto en un arca y cuando por fin se logra la unanimidad, algunos "que avian puesto lo contrario de esto tiraron las cédulas primeras del arca e pusieron otras en las quales se contenía que tenian por el testamento simplemente...; e tomaron los Procuradores del Regno el arca con estas células e fuéronse para el castillo do estaba el Rey e presentáronle el arca do estaban las dichas cédulas, e abriéronla, e fallaron que todos querían estar por el dicho testamento...» (cap. 4), que no pone fin a los enfrentamientos pues de los seis tutores designados por Juan, el arzobispo de Toledo cuenta con los votos del marqués de Villena y del duque de Niebla, y el arzobispo de Santiago tiene el apoyo de Gonzalo Núnez de Guzmán, maestre de Calatrava, y de Juan Hurtado de Mendoza, Alférez de Juan ${ }^{27}$.

Fueron, sin duda, estos enfrentamientos, que llevaron a la detención del arzobispo toledano y a la puesta de la tierra en entredicho ${ }^{28}$ los que hicieron a Enrique III declararse mayor de edad dos meses antes de cumplir los catorce años. Ante él, en el monasterio de Las Huelgas de Burgos rindió cuentas de su actuación, en nombre de los tutores, el arzobispo de Santiago que recurre a los similes marineros: el "mareante", el marino no ha de ser alabado al comienzo de su viaje ni en el medio sino al tinal, cuando llega a puerto y "consumación buena de su viage»; los tutores han llegado al final y como buenos mareantes han hecho gala de tres virtudes: humildad, discreción y acción de buenas obras. Humildes, porque "sofrieron muchas sosañas e muchas quejas de grandes e

27 Puede verse el testamento en el capítulo 6 de 1392.

${ }^{28}$ Según el derecho canónico, la detención de un prelado lleva consigo automáticamente la puesta en entredicho de la tierra del obispado o arzobispado y de los dos obispados más próximos y la excomunión de cuantos intervienen. Mientras dura el entredicho no se pueden celebrar los oficios divinos en la tierra y alli donde iba el rey unon se decian horas" (cap. 15 de 1393). 
medianos e pequeños, por guardar vuestro servicio»; discretos, aunque gastaron más de lo que debían, porque siempre entendieron que era discreción contentar a los Grandes y «aún a los otros Señores menores... aunque el dinero se gastase, porque vos... fallásedes vuestro Regno entero e unido; ca las rentas, loado sea Dios, cada año vienen, e lo que se daba, en los vuestros se despendia...". Las buenas obras se concretan en que, a pesar de los enfrentamientos entre los tutores, «non ovo muertes, nin cruezas, como ovo en algunas tutorias de los Reyes vuestros antecesores, segund se lee en las Corónicas e se acuerdan hoy dello algunos omes antiguos que son vivos e lo vieron...". Si de los principios se pasa al terreno de los hechos concretos, la actuación de los tutores puede concretarse en el mantenimiento de las paces, treguas y alianzas con Granada, Portugal y Francia, en el pago de las cantidades debidas al duque de Lancaster, en la conservación del patrimonio regio sin enajenar ni una almena y en la reducción de la alcabala a la mitad: en lugar de pagar la "decena de las véndidas e compras... en el comienzo del regimiento lo tornaron a veintena, que es la mitad menos". Llegados a buen puerto y ventura, puesto que han dado cumplida cuenta de las mercaderías que les fueron confiadas, piden "que si en alguna cosa, por non lo poder mejor alcanzar, vos han fallescido, que sean perdonados", petición que fue aceptada por el Rey que, en adelante, gobernará por sí mismo a pesar de su edad (cap. 17).

\subsection{El gobierno personal}

Someter a la nobleza, representada y dirigida por los familiares del monarca, y controlar a las ciudades que han adquirido gran fuerza durante los años de la minoría ${ }^{29}$ son los objetivos de Enrique III, en cuyo reinado la situación internacional apenas experimenta variaciones: se mantienen la alianza con la monarquía francesa y la obediencia al papa de Aviñón, continúan las treguas con Portugal y Granada... ${ }^{30}$.

${ }^{29}$ Los interesados en la historia de Vizcaya disponen, en el capítulo 19 de 1393, de una detallada narración del viaje hecho por el monarca para tomar posesión del Señorio, y de las peticiones y exigencias de los vizcaínos.

El capitulo 20 recoge noticias sobre una de las expediciones de "gentes de Sevilla e de las costas de Vizcaya e de Guipúzcoa" a las Islas Canarias.

30 La paz con Granada fue rota por el celo intempestivo de Martin Yánez de la Barbuda, maestre de Alcántara, que envió una carta de desatio al rey granadino: "él se combatiría con él e con los que él quisiese, con avantaja de la mitad más, en guisa que si los Moros fuesen doscientos, quél tomaría ciento de los Christianos...". El desafío no fue acep- 
Las Cortes son reunidas en Madrid para obtener ayuda económica y confirmar los acuerdos y treguas con el duque de Lancaster, con Portugal y con Francia, aunque el aspecto fundamental es la ayuda económica para hacer frente a las necesidades cotidianas y "pagar algunas debdas que su padre dexara"; el monarca muestra su buena voluntad ofreciéndose a mostrar las cuentas, y los procuradores responden que previamente el rey debería organizarse y reducir gastos, por ejemplo, en el ordenamiento de las lanzas: el rey daba una cantidad a los nobles y éstos se obligaban con este dinero a contratar, al servicio del rey, un determinado número de hombres de armas y en la práctica sólo contrataban a la mitad y así cuando el rey creía tener cuatro mil hombres, sólo dispone de dos mil "e el defendimiento del Regno menoscábase mucho por ende". Con esta salvedad, y a pesar de que los gastos se han reducido por estar el reino en paz con Aragón, Inglaterra, Granada y Portugal, le dan como ayuda la "alcabala veintena" y seis monedas ${ }^{31}$ que rentarán doce y seis millones de maravedies a los que se unirán las rentas ordinarias de ia monarquia que entre foros, salinas, diezmos de mar y tierra, juderías y portazgos ascendian a siete millones; las Cortes consideran que con un total de veintiocho millones de maravedies es suficiente y piden un compromiso de que "non echaredes este año otro pecho nin pedido en el Regno..." y si quisiera hacerlo que fuese siempre en reunión de Cortes.

La petición inicial de treinta y cinco millones de maravedies se vio reducida y obligó a limitar gastos por lo que Enrique anuló las gracias y mercedes hechas por los tutores, pero sin éxito, pues como recuerda Ayala y repetirá en el Rimado de Palacio, sus consejeros «facianle facer otros crecimientos de nuevo, diciendo que facian en ello su servicio, e que los tales era razón de ser contentados; e lo que non osaban facer antes de los catorce años, facianlo después de los catorce". Estos abusos no impidieron que en las Cortes se reordenaran las nóminas de las tierras «e mercedes e mantenimientos que tenían dél los señores e caballeros e otras personas del Regno...", y por cuanto los familiares del monarca, la reina de Navarra, el duque de Benavente, el conde Alfonso de Noreña y el conde Alfonso habían recibido numerosas donaciones

tado, el maestre penetró en tierras de Granada con trescientas lanzas, mil hombres de a pie "y una cruz alta en una vara e su pendón cerca de la cruz", y todos los caballeros murieron asi como muchos de los que se unieron a él en Córdoba (caps. 8 a 12 de 1394).

${ }^{31}$ La moneda era un impuesto que se pagaba al monarca al comienzo del reinado y cada siete años en reconocimiento de su poder. Cada moneda equivale a ocho maravedies en Castilla, las Extremaduras y la frontera, y seis en León. 
durante la minoría, los Contadores ordenaron "que les fuesen libradas aquellas contías que tenian del Rey Don Juan quando era vivo, e non más...» (caps. 21 a 26 de 1393).

La reducción de sus cuantías es la primera medida contra los familiares del monarca, a los que se ofrecerá la paz y se combatirá militarmente cuando fracasen las negociaciones. El caso más llamativo es, sin duda, el de la infanta Leonor, reclamada una vez más por su marido, Carlos III de Navarra, "para aver su vida honrada segund que deven marido e muger»; en esta ocasión, la petición del monarca navarro fue atendida quizá por creer Enrique que la reina «era aliada con el Duque de Benavente e con el Conde Don Alfonso, sus hermanos, e con el Conde Don Pedro, su primo"; a comienzos de 1395, Enrique acompañaba a Leonor hasta la frontera y sus embajadores tomaban juramento en Tudela al monarca navarro de que "todas las informaciones e miedos e temores que a la Reyna su muger avían puesto de él, que eran mintrosos, e que siempre fuera su voluntad de la mirar e amar e honrar asi como era razón de amar e honrar a su muger», con lo que desaparecían las últimas excusas de Leonor para permanecer en Castilla (caps. 4 y 19 de 1394, 1-3 de 1395...).

Fadrique de Benavente no espera a que los tesoreros del rey le entreguen el dinero concedido por el monarca, se hace pagar directamente y responde con el silencio a los avisos del monarca hasta que éste lo cita en Valladolid y le obliga a aceptar determinadas condiciones: hacer cuentas con los tesoreros y devolver lo que hubiera tomado en exceso, y entregar como rehenes dos hijos bastardos así como los castillos de Medina de Rioseco y Tordehumos. La avenencia tiene para el monarca un precio económico: en lugar de los cientos ochenta mil maravedies anuales que le habian asignado las Cortes de Madrid, recibiria quinientos mil, que no fueron suficientes para poner fin a las conspiraciones del duque de Benavente. Éste fue detenido el 25 de julio de 1394 y confiscados todos sus bienes (caps. 1-7, 13-17, 24-25 de 1394...).

Alfonso de Noreña llevó su revuelta hasta la guerra contra el monarca que se vio obligado a combatir militarmente los dominios del conde en Asturias y a someter sus diferencias al juicio del rey de Francia, que habria de juzgar de acuerdo con los "fueros e leyes de Castilla"; los representantes de Alfonso llegaron a la Corte francesa con retraso y utilizaron el viaje para reclutar hombres de armas hasta que el rey de Francia le prohibió sacar del reino "omes de armas nin arneses más de los que él trojera quando vino" y ordenó a sus hombres que no le dejasen adquirir navios, armas, viandas... Seguro del apoyo francés, Enrique 
cercó Gijón por mar y tierra hasta que lo tomó y cmandó derribar la villa e castillo de Gijón...» (caps. 28-31 de 1394 y 5-9 de 1395).

\subsection{De nuevo el Cisma}

En esta última crónica, Pedro López de Ayala no puede olvidar la división de la Iglesia, en la que aparece un elemento nuevo en 1394: a la muerte de Clemente VII, papa de Aviñón, los cardenales electores firman un escrito por el que se comprometen a buscar ante todo la unión de la Iglesia e incluso a renunciar al papazgo si fueran elegidos si a los cardenales les pareciera necesario. La elección recayó sobre el aragonés Pedro de Luna que tomó el nombre de Benedicto XIII y al que la Historia conoce como el "papa Luna", que se negó a renunciar cuando se propuso formalmente la renuncia de ambos papas y propuso otra solución: que él y sus cardenales se reunieran en lugar seguro con el que se decía papa de Roma y sus cardenales y juntos propusieran una solución que Benedicto tiene clara pero que no hace pública para que no llegue a oídos de los adversarios y puedan éstos "ordenar muchos engaños, por lo qual podría la pestilencial malicia de los que cisma e departimiento acarrearon... durar más luengamente...". El acuerdo entre el pontífice y sus cardenales, sometidos a la influencia de los consejeros del rey de Francia, no fue posible y la Crónica de Pedro López de Ayala finaliza con la reproducción de una cédula de Benedicto XIII por la que prohíbe a sus cardenales adherirse a un escrito de los duques de Francia para que no pudiera haber dudas sobre la "libertad de la iglesia" (caps. 11. 22 de 1395).

Las diferencias entre los duques y el papa aviñonés tienen que ver con las paces firmadas entre Inglaterra y Francia a las que alude el cronista en el año 1396 cuando describe la extraordinaria fiesta cortesana que acompañó al matrimonio de Isabel de Francia con Ricardo de Inglaterra. El dia de su matrimonio, Isabel pide a su padre tres favores o gracias especiales y la primera es que los reyes de Francia e Inglaterra traten de «la unión de la Iglesia de Dios, que tanto cumple a la Christiandad"... y que tanto interesó a nuestro cronista Pedro López de Ayala, que se ocupa del Cisma en el Rimado de Palacio y, como hemos visto repetidamente, en las crónicas de Enrique II, Juan I y Enrique III. 